5G.002 IMPROVING STRUCTURAL SAFETY BY SHARING LESSONS LEARNED

Michael Fordyce*, Peter Ho. CROSS-AUS Ltd, Kenmore Hills, Australia

10.1136/injuryprev-2021-safety. 141

CROSS-AUS (Confidential Reporting on Structural Safety Australasia) is a confidential reporting system established in Australasia in 2018 to capture and share lessons learned from structural safety issues which might not otherwise get public recognition, with the aim of preventing future failures.

Confidential reporting is a well-established safety procedure, especially in aviation, and CROSS-AUS builds on the success of CROSS-UK, the unique UK based system which has been operating since 2005 and is part of a growing network of CROSS programmes internationally.

The Shergold Weir report, Building Confidence, published in 2018, highlighted a wide range of problems in the Australian construction industry and concluded 'It is our considered view that the nature and extent of the problems put to us are significant and concerning. They are likely to undermine public trust in the health and safety of buildings if they are not addressed in a comprehensive manner.'

It is important that the structural engineering community plays it part in restoring confidence in our industry, and CROSS-AUS provides a vehicle whereby everyone can contribute towards improving quality and safety by sharing safety issues and disseminating advice on good practice. The paper will describe the processes used by CROSS-AUS and provide examples of instances where beneficial changes have resulted. Ultimately the intention is to have a global freely available database to be used by the construction industry anywhere to improve the safety of their buildings, structures, and national infrastructure.

\section{G.003 ENGINEERING DESIGN AND THE ROLE OF THE SAFETY PRACTITIONER}

Angela Petts*. Engineering. Systems. Management., Adelaide, Australia

10.1136/injuryprev-2021-safety. 142

The role of the modern safety practitioner is diverse. There are many elements and areas of specialisation within a safety management system.

Safety in Design is hazard management throughout the engineering design lifecycle. It is a function of engineering; it is also a safety management system element.

Safety-related activities embedded in engineering typically relate to the top of the Hierarchy of Controls and therefore present the most effective opportunity for injury prevention.

The safety practitioner will, at some point, need to operate in this space. This will likely be through audit and compliance activities as well as participation in hazard and engineering studies for new design and design modifications, handover, verification and validation.

As a conversation starter, the presenter will provide a concise answer to these questions, based on experience and observation:

How does engineering design feature in the role of safety practitioner?
What can the engineering team expect of the safety practitioner?

What should the safety practitioner expect of the engineering team?

Is the safety practitioner equipped with the right knowledge to confidently operate in this area?

\section{G.004 ENGINEERED SAFETY GROUP - TOOLS AND TECHNIQUES FOR SAFER DESIGNS}

Mike Hurd*. Engineers Australia - Engineered Safety Group, Adelaide, Australia

10.1136/injuryprev-2021-safety. 143

According to numerous national and international studies, around $35 \%$ of workplace incidents, injuries and fatalities have causal factors related to design. This emphasises the opportunity for engineers and designers to prevent injury through deliberate interventions to address safety during the design stage.

In 2013, the Engineers Australia, Engineered Safety Group was created, comprising engineering, education and safety professionals from varied backgrounds. With the aim of preventing workplace injuries related to design, the group works to discuss, enhance, test and promote a set of leading practice Safety in Design tools and techniques that can be applied across engineering disciplines and industries.

In this presentation, Mike Hurd, inaugurator and former chair of the Engineered Safety Group, will present on the learnings of the group, the key elements of safe design, and how the group continues to promote safe design in academia and industry.

\section{G.005 IS OUR FOCUS ON RISK MISPLACED?}

Trevor Zwar*, Mike Hurd, Angela Petts. Engineering. Systems. Management., Adelaide, Australia

\subsection{6/injuryprev-2021-safety. 144}

Risk assessment is often the primary tool used by designers to evaluate and guide the treatment of safety issues associated with their design. However, workplace health and safety legislation requires that all reasonably practicable controls be incorporated into the design. Therefore, the assessment and ranking of risk, which often occurs through the selection of qualitative values for likelihood and consequence, open to uninformed interpretation and manipulation, may not be the best tool for the task.

Leading practice Safety in Design processes focus on the systematic identification of hazards early in the design followed by the selection and implementation of all reasonably practicable controls. The justification of included controls through risk assessment is not necessary. Where reasonable practicability for a particular control is uncertain, a determination may be made by evaluating whether the whole-of-life cost of the control is grossly disproportionate with the reduction in risk, where the risk is quantitively determined using statistical likelihood and consequence values.

Using this approach; risk assessment may be a useful tool at the end of the hazard treatment process for the 